The University of San Francisco

USF Scholarship: a digital repository @ Gleeson Library |

Geschke Center

Public and Nonprofit Administration

School of Management

2014

\title{
Aligning Fiscal and Environmental Sustainability
}

Richard Callahan

University of San Francisco, rfcallahan@usfca.edu

Mark Pisano

Follow this and additional works at: http://repository.usfca.edu/pna

Part of the Environmental Policy Commons

\section{Recommended Citation}

Richard F. Callahan and Mark Pisano. Aligning fiscal and environmental sustainability, in The Elgar Companion to Sustainable Cities: Strategies, Methods and Outlook. Blanco, Hilda, Mazmanian, Daniel A, eds. Edward Elgar Pub. Ltd. 2014. Pages 154-165. DOI: $10.4337 / 9780857939999.00013$ 


\section{Aligning fiscal and environmental sustainability \\ Richard F. Callahan and Mark Pisano}

\section{INTRODUCTION}

The future of environmental sustainability will be driven by the capacity of local, state and federal levels of government to develop fiscal sustainability. For example, in the case of the Alameda Corridor in Los Angeles County environmental sustainability advanced only because of the fiscal sustainability of the project. The environmental improvements of reducing particulate car and truck pollutants, as well as remediation of underground water pollution, were financed by the innovative public-private partnership that generated revenues to pay for long-neglected environmental degradations (Callahan 2007).

The Alameda Corridor rail construction case illustrates a small but emerging set of cases showing local government leaders linking fiscal decisions to environmental issues (Wang et al. 2013), as well as the connection of public administration and environmental sustainability (Fiorino 2010). In research on leadership adaptation to fiscal stress, a recent set of case studies offered practical lessons for connecting fiscal and environmental sustainability (Pisano and Callahan 2012; 2013). These practices include: framing fiscal stress as a catalyst for addressing long-term natural resource needs, done recently in San Bernardino County; developing fiscal expertise before a crisis, in Los Angeles County; and more inclusive budget processes to develop trust, as found in the Whittier School District (RubioCortes 2012). The findings from these and other cases offer actionable lessons for leaders in the public sector and communities to link environmental and fiscal sustainability. This chapter describes examples of fiscal sustainability that can fund environmental sustainability.

In part, this chapter draws on the recent findings from a three-year research project on local government fiscal sustainability funded by the Haynes Foundation. In this research, local government is not synonymous with small units of government. The eight case studies include a fiscal giant of local government, Los Angeles County, with over a $\$ 23$ billion annual budget; San Bernardino, the largest geographic county in the USA; and the large cities of Long Beach (McGrath 2012b) and Santa Ana with 
populations of over 200000 each, as well as smaller cities and school districts. The research findings from these cases develop from the following questions: do the findings on fiscal sustainability have implications for the understanding of environmental sustainability? Do the findings on fiscal decision-making processes and strategy offer insights for institutional design and strategy that shift from short-term outlooks to accounting for long-term fiscal and environmental impacts?

This chapter's findings illustrate an interconnectedness of local government fiscal sustainability and environmental fiscal sustainability. One of the cases, San Bernardino County (Pisano and Callahan 2013), offers a vivid example strategy in the context of budget shortfalls that nonetheless moved forward by bringing together city governments and other stakeholders to address long-term environmental needs, in particular water allocation and growth, through a general plan coordinated across various cities and county government.

This chapter outlines the nested relationship between fiscal sustainability and environmental sustainability in local and regional governments. Of practical application are the ways that the varied findings explain how leaders can change organizational behaviors through institutional redesign to advance both environmental and fiscal sustainability. If 'all politics are local', in the aphorism attributed to former Speaker of the House, Tip O'Neil, then all environmental impacts are likewise political with local impacts. The first section of this chapter addresses emerging practices of fiscal sustainability; the second section reviews the challenges of aligning fiscal and environmental decision making; the third section considers how to connect land use, housing, transportation and air quality; the fourth section offers a case study that links long-range planning and budgeting, including practices on water sustainability and an international fiscal study; the final section suggests three central features for effective political strategy to advance sustainability.

\section{EMERGING PRACTICES FOR FISCAL SUSTAINABILITY}

The evolution of budget deliberations has shifted fundamentally to a context of scarcity. No longer are there discussions of how to increase funding for expanded and new programs; rather, there is recognition of limited financial resources (Pisano and Callahan 2012) leading to a question of what can be funded. An expert panel review of the fiscal sustainability case studies outlined a conflict in world views as to whether the economic downturn is temporary, calling for fiscal strategies that bridge 
the gap in revenues until an upturn, in contrast to a view that the downturn is permanent with continued fiscal deficits.

Research forecasts a new normal of increasing fiscal constraints for decades, driven by revenue stagnation and demographics of aging taxpayers (US GAO 2012; Pisano 2013). Additionally, there are pressures that are cyclical, structural and intergovernmental (Chapman 2008), coupled with expectations from residents wanting increased services with decreased taxation (Korey 2011). These constraints suggest the need to rethink policies developed in times of relative abundance. The duration of fiscal stress at all levels of government - but experienced most harshly at the local and state levels, where operating deficits are not constitutionally permissible will drive transformation and change. The cases researched on fiscal sustainability suggest practices that shift from short-term focuses to decision-making processes that account for long-term impact. The lessons from research on eight case studies of fiscal sustainability (Callahan 2012; Pisano and Callahan 2012; McGrath 2012a; 2012b; Rubio-Cortes 2012; Pisano and Callahan 2013) collectively suggest the following effective practices:

1. Leadership needs a robust understanding of fiscal sustainability. For some, sustainability simply refers to the ability to balance the budget from year to year. There are conceptual and practical limits in considering sustainability as simply balancing the budget through expenditure reductions. The complexity of intergovernmental financial flows, the need to understand enterprise financing and variable economic conditions, requires an increasing fiscal literacy.

2. Long-term thinking needs to account for the full cost of projects both for construction and lifetime maintenance for capital projects of collective bargaining, and of externalities. The difference between budgeting and fiscal sustainability was addressed by Los Angeles County leadership using the following definition: 'include only known resources in the annual budget and make decisions based on long term and full costing; manage strategically to maximize resources; and develop partnerships and innovation in financing to accomplish the needs of the county'. This approach has led to fiscal integrity that keeps options open for future generations, potentially a transformative redefinition of budgets.

3. Trust is a journey. Earning and retaining trust as a 'reserve', allows public organizations to be sustained in a variable financial world. The leadership of the Whittier Union High School District exemplified the practices of building trust in the community in both educational quality and the effective management of financial resources. 
Leadership practices of transparency, meaningful engagement and effective communication increased trust that enabled difficult public elections on property tax increases to succeed in difficult economic times.

4. Leaders change the organizational culture to advance fiscal integrity. Organizational culture developed from committing to fiscal integrity, working across departments and programs, engaging key stakeholders as problem solvers, developing administrative expertise, and shifting toward risk-adverse fiscal models. Finally, clear and transparent executive accountability is needed to for difficult decision making, efficient execution and adherence to budget targets.

5. There is a need to see fiscal sustainability as part of a system. The systems view provided an analytical framework to identify leverage points that can affect outcomes in the long term. Leadership both reduced the cost of services and developed innovative ways to maintain services. A systems approach integrated initiatives, found economies of scale, developed incentives, and identified impacts across silos, departments and units of a jurisdiction.

\section{THE CHALLENGES OF ALIGNING FISCAL AND ENVIRONMENTAL DECISION MAKING}

The first practical, but surprisingly difficult, step for connecting fiscal and environmental sustainability is to confront the actual reality. The lack of alignment between fiscal and environmental sustainability results from societal discussions trapped in outdated ways of thinking and acting. Conventional practice in the public sector at the local, regional, state and federal levels does not connect fiscal and environmental sustainability. Current governmental practices create an adversarial context between fiscal and environmental sustainability. Elected officials conduct budget deliberations and environmental impact reports in separate contexts and in different public hearings. The processes for fiscal issues and environmental issues differ in the authorizing legislation, with divergent practices evolving over the past several decades.

Similarly, local government processes typically do not connect comprehensive general plans with the budgeting activity of local and state government. Comprehensive land-use and transportation plans have long-term horizons; budgets seldom extend beyond one year. Good comprehensive plans are linked to a business plan with return on investment calculations needed for fiscal sustainability. The budgets of state and local/regional governments are year to year, with the Legislative Analyst of the State 
of California looking ahead five years. Comprehensive plans, as well as environmental plans, look at the effects of demographic cycles on their decisions. All budget practices at the local and state levels fail to look at the changing demographic cycles and fail to rethink fundamental assumptions.

The challenge in fiscal and environmental sustainability is linking these unconnected elements. This linkage would leverage assets for long-term outcomes, measurable in time and amount. Framing the public sector decision-making processes as a strategy puzzle that considers the range of assets provides a context for considering the budget and the environment as a set of assets rather than two distinct sets of constraints. A range of examples in transportation and air quality at the regional and federal levels offers evidence of the disconnection between financing and environmental approvals. Spending on transportation planning and environmental documents on environmental externalities can have a statement of overriding consideration, ultimately making it hard to realize the desired goals. In California, as well as in the federal system, institutional design penalizes itself by not linking environmental sustainability with fiscal sustainability.

In project decision making, sustainability calls for developing a business plan for the project that is based on the utility of the investments, the amount consumers are willing to pay, and building the project on this agreed financial structure. The Alameda Corridor and the toll roads in Orange County were planned and developed using a business plan model. These projects were required to achieve transportation, environmental and equity goals before being included in the Regional Plan of SCAG that conformed to the region's air quality plan. Finally, these projects align those who benefit with those who pay. This approach to project development requires users and consumers to be supportive and willing to pay for project development.

\section{CONNECTING LAND USE, HOUSING, TRANSPORTATION AND AIR QUALITY}

There are examples that link land use, housing, transportation and air quality with encouraging results. The blueprint of strategies of the Southern California Association of Governments and the Sacramento Area Council of Governments that linked transportation, energy and air quality showed gains in all aspects at a reduced cost, leading to the passage of state law SB 375 that required development of the Sustainability Community Program. Each region has developed a long-range land-use plan that links new development patterns with transportation investments. A practical step has been the focus of these plans on outcome-based proc- 
esses. The combined sustainability strategy was required to demonstrate vehicle miles traveled, $\mathrm{CO}_{2}$ emissions and energy consumption reductions. Connecting more efficient land use with transportation improvements benefits each and can be accomplished at less cost.

In the case of SCAG, the regional land-use plan was based on a regional return on investment strategy that linked land-use policies and transportation investments to return on investments calculations that would provide economic and financial sustainability. The distinctive feature of the 2012 SCAG Transportation Plan was the effort to work with local government through workshops at the local, sub-regional and regional levels, as opposed to imposing mandates on local government. The sustainability of the environmental goals became linked to developing shared commitments across local governments. Building the regional plan from the bottom up was made possible by the regional systems modeling and information processes. $\mathrm{CO}_{2}$ reductions of the regional plans are submitted to the Air Resources District for approval as part of the state's climate change initiative.

Financing remains the ultimate test of whether a sustainability strategy that is less costly can be implemented, which means that annual fiscal and budgeting decisions remain in place. If sustainability strategies can be shown as less costly, and have a positive return on investment (ROI) calculation, then revenues can be generated by the participating entities. Revenues can be derived by jurisdictions providing they have the right institutional design to captures these efficiencies and ROI. The lessons learned from the budgets in the case studies suggest practices for the 186 jurisdictions in the SCAG and the 27 jurisdictions in the SACOG region to help formulate approaches that capture revenues, creating budgets that are more sustainable.

Infill development with mixed use that is distributed throughout the region is the dominant urban form in these strategies. While the state has eliminated redevelopment as a tool for financing, there are a number of other California statutes that have been enacted in the past and can be used now, such as the Infrastructure Financing Investment Act and the Infrastructure Financing Act or Assessment Districts. Another possible source for financing the investments for these sustainability plans is the Cap and Trade Program that the State of California has developed to assist in implementing the state's Climate Change Program. The Air Resources Board (ARB) charges emitters of $\mathrm{CO}_{2}$ and pays reducers. If the resulting emission reductions of the regional sustainability program are achieved, and are cost-effective as envisioned, the cities and counties could obtain resources under the Cap and Trade Program for these investments. To be successful, these financing provisions require new institutional designs. 
The lessons gained from the case studies become a way to develop institutional designs that realize fiscal gains.

\section{LINKING LONG-RANGE PLANNING AND BUDGETING: A SURVIVAL GUIDE}

The leadership of the County of San Bernardino had struggled with the economic downturn and public corruption issues in the past decade. This county, perhaps more than any other area of the country, has been shocked by the economic transformation of the country: housing bubble burst, industrial closings and military base closures, and other dysfunctional internal stresses. The major city in the county, the City of San Bernardino, has filed for bankruptcy. The county turnaround began with new leadership (Pisano and Callahan 2013) that outlined a ten-year budget plan framework to project the future costs of previously adopted policies. Starting in 2010, the county leadership initiated reform and transformation that directly link long-range planning with long-range budget reform. The practical steps that leadership in San Bernardino County applied were similar to other cases, particularly the County of Los Angeles:

- included only actual - not projected - revenues;

- considered the long-term costs and revenue projects;

- calculated life-cycle costs in developing the general fund budget;

- developed partnerships beyond the current budget year.

The linkage between budgetary and environmental sustainability in this case study offers evidence for the possibility of success in times of profound fiscal stress. The most important practical step for the County of San Bernardino County's chief executive officer was to engage all the public jurisdictions and districts in a long-run growth and development discussion. The county used the staff, skills, and tools of planning and communications within the county government and across the cities in the county. The Council of Governments for the county convened a process that developed an economic growth strategy as well as a partnering strategy with cities and the county in this vast geographical area to share in the delivery of services and the management of parks. Key in the long-run vision were the issues of housing foreclosures and water supply. The plan operationalized annual targets and milestones that had budgetary consequences tied back to the county-elected and -appointed officials' deliberations on the long-run budget.

The partnership strategy that is essential in resolving fiscal and envi- 
ronmental sustainability is found in the County of San Bernardino. Its leadership demonstrated that fiscal sustainability and environmental sustainability do not have to be separate decision-making processes. Along similar lines, the budgetary process is linking a county-wide coordinated city and county general plan to assist in the resolution of the housing and economic base rebuilding. An important innovation tested in the county-wide plan was the inclusion of a pioneering initiative in the City of Ontario. This initiative included in the general plan an economic strategy as its foundational starting point for zoning. The city started with an economic strategy that would support the needs of its citizens as well as the fiscal long-term needs of the city. A key element of the plan was the development of the airport infrastructure of Ontario Airport and the related logistics sector that springs from it. The city- and county-coordinated plan extended Ontario's approach to the joint county-wide effort to rebuild the economic base of the county and the adjacent County of Riverside. A strategy for revitalizing the housing stock, devastated by the housing market collapse, also included use of the Sustainable Cities Strategy of the SCAG Regional Transportation Plan.

The County of San Bernardino leadership concluded that the issue that most threatened both future fiscal and environmental sustainability was water supply - not surprising for a desert region. As part of the visioning effort, the water agencies were charged to develop a strategy that would address this issue through coordination and cooperation of all entities within the vast region. The approach deliberately did not just rely on past practices of water management, acquiring water from beyond the region. Strategies of conservation, new urban development forms, changes in the economic base that are less demanding, reuse of the scarce resource, capture of runoff and green development were all considered. Lastly, costs and financing that would need to be part of the annual budgeting process of jurisdictions and faced by consumers and businesses were a major consideration, so as not to jeopardize the county's competitiveness. Actions needed to develop a more sustainable, diverse and decentralized water supply will require new ways of doing business in the future.

The approach taken in San Bernardino is now being extended to other parts of Southern California. The Metropolitan Water District's Blue Ribbon Committee MWD 2060 developed a similar strategy for the entire region. The key design feature of this regional strategy is decentralized activity that relies on more efficient and lower-cost strategies emerging through new institutional design, similar to the practices being followed in the examples of air quality and transportation.

Shifting to an international example, fiscal sustainability research partners in Germany have identified decentralized sustainability programs 
where municipalities are a key building block for these initiatives. The research team that conducted the local government fiscal sustainability case studies has undertaken a joint research program with the University of Kehl, to explore how fiscal and environmental sustainability are being implemented. Germany requires that all budgets have a three-year time horizon. The City of Freiburg, which is in the research area, has voluntarily extended this to a ten-year time frame for many of the reasons cited in the above examples. The development of policy for solid waste disposal is an example of linking environmental sustainability and cost reductions in that city's long-term budget.

\section{POLITICAL STRATEGY TO ADVANCE SUSTAINABILITY}

Fundamentally, the question for fiscal and environmental sustainability is: how does cooperation emerge in a political environment that presently is highly charged? This challenge is shared across contemporary American experience with constitutional democracy as characterized by turbulence and a search for reasonableness (Newland 2012). In effect, the challenge of accounting for fiscal and environmental sustainability in a turbulent public decision-making processes is the challenge of politics.

As part of a political strategy, innovations in technology have proven effective in advancing sustainability. Technological advances, in part, mitigated the dire forecasts of the Club of Rome report in the 1970s. Changes in technology involve risk, further emphasizing the need for a political strategy that focuses on risk identification, risk mitigation and risk management, and away from risk avoidance. To accomplish this change, procurement processes will need to become outcome based and not specification based and employ the same systems, life-cycle and institution design principles. The system evaluation capacities that have been developed in space and military successes by the Aerospace Corporation for NASA and the US Air Force can be adapted for domestic needs and environmental needs. The National Academy of Public Administration, undertaking institutional and policy design, and the Aerospace Corporation, undertaking systems and technical evaluations, have developed a partnership to advance this connection.

In effect, challenges of a transforming context and turbulent public decision-making processes are challenges of politics. What is missing is political strategy on how to develop a constituency for fiscal and environmental sustainability and the tools to link these constituencies. Developing a constituency for environmental and fiscal sustainability is difficult to 
attain for our collective goods goals because we have not linked these objectives to implement either. This has been done in the national cultural changing constituency for clean air, water and parks over the past several decades. The constituencies across a range of stakeholders, individual and associations, for environmental protection emerged only in the 1960s. At the core of various ideologically driven questions is the uncertainty of a future capacity to pursue fiscal and environmental sustainability.

Developing constituencies for fiscal sustainability calls for a transition from partisan politics to a strategy that includes a range of associations, from environmental, fiscal watch dogs, business, government and labor, and individuals who are not transitory but can regularly engage, over a period of a decade or more, in policy-making discussion and electoral politics. San Bernardino County's approach is an example. A strategic approach will engage citizens beyond special-purpose interest to use all resources, both environmental and financial, in more effective ways. Moreover, the need to look long term will bind these interests into a set of mutual interdependencies that will require trust building, which was the case in Los Angeles County, where the pension negotiations that followed these characteristics have generated a sustainable large-scale pension program (Pisano and Callahan 2012).

Strategy also needs to communicate the similarity of the rules of the game - in effect the institutional features common to both fiscal and environmental sustainability, as well as the need to redesign institutional features to move from ineffective path dependency. More effective communication is needed to deal with the fiscal and financial debt threat at all levels of government. As part of a communication strategy, iterative dialogue through learning forums (Moynihan 2008) offers tangible practices that can improve performance over time. The practices of effective communication include discussion of the long-term impacts, the use of the tools of system planning, information systems, pricing and consumer information. This iterative dialogue can develop an organizational culture that engages each of the sectors, creates a political strategy that binds us together and reverses the divisions that are pulling us apart.

The strategy that is emerging from all the cases and examples described above is to complement the use of existing revenues derived from our tax base with partnerships and the nexus of beneficial use payments of consumers. The dynamics needed are to align the beneficiaries who are consumers and taxpayers. When this is done, individuals become the decision makers and, in the process, over time, both change their behavior and become part of the problem solving of both issues. More revenue is brought to the table and more problem solvers are involved and new coalitions emerge. Ignoring this strategic approach and failing to add capacity 
to address the common goods results in those who are affected most, the disadvantaged, suffering the greatest harm. The inability to build a political solution to the fiscal and environmental sustainability challenges will result in larger numbers of those least able to afford or absorb the impact being adversely affected. A political strategy is needed to include more of the benefits of a sustainable society, to advance the three Es: economics, environment and equity.

\section{CONCLUSION}

Environmental sustainability has been disconnected from financial decisions, with budgets and financing operating with a short-term focus, not connected to principles of sustainability, and with both goals thought to be unattainable and incompatible. Our research on fiscal sustainability suggests the potential for practical steps that link environmental and fiscal sustainability in local government decision making. These are steps that in the aggregate can address the most fundamental challenges facing local, state and national levels of government.

The starting point is to change the decision-making process for both budgets and environment to outcomes and results that can be explained in ways that the public can relate to and understand without referencing specific programs, projects and initiatives. The tools of planning need to be used in both processes so that assumptions can be made explicit and understood, using a language that enables decision makers to anticipate both the immediate as well as the long-term costs. Given the advanced information and analytical tools that we have today, the long-term cost can include the externalities that decisions have on society where the impacts of one decision form part of the costs of another. Actual environmental and fiscal returns on investments can occur, for example in the City of Brea's purchase of a solar system built by Chevron on top of their city hall to reduce their electricity bill as part of their budget decision making (McGrath 2012a).

Getting life-cycle costs correct - including externalities - creates opportunities for more sustainability in project development. Aligning those who benefit with those who pay for new projects can also create fiscal and environmental returns on investments. This principle is based on a recent change, with world consumers of private and public goods becoming the primary decision makers. Coupling planning and information systems with a redesign of institutions will enable public sector leaders to replicate in the public space what is happening in the market space. These changes will enable individuals to be consumers, taxpayers and providers by changing their behavior. 
Shifting from a perspective of environmental sustainability as an abstraction to the connection of fiscal sustainability practices in local government advances both concepts. The practical steps outlined in the chapter advance a connection of environmental and fiscal sustainability, facilitating future iterations of the budget processes to use environmental and fiscal resources more wisely.

\section{REFERENCES}

Callahan, R.F. (2007), 'Governance: the collision of politics and cooperation', Public Administration Review, 67 (2), 290-301.

Callahan, R.F. (2012), 'Moving beyond magical thinking: finding leadership, strategy, and fiscal sustainability in local government', National Civic Review, 101 (1), 8-10.

Chapman, J.I. (2008), 'State and fiscal sustainability: the challenges', Public Administration Review, 68 (S1), S115-S131.

Fiorino, D.J. (2010), 'Sustainability as a conceptual focus for public administration', Public Administration Review, 70 (S1), S78-S88.

Korey, J.L. (2011), 'California: a failed state or too big to fail?', The California Journal of Politics \& Policy, 3 (2), 1-21.

McGrath, M. (2012a), 'Case study IV: fiscal sustainability and bottom-up change in Brea, California', National Civic Review, 101 (1), 30-34.

McGrath, M. (2012b), 'Case study II: fiscal sustainability and political culture in Long Beach, California', National Civic Review, 101 (1), 18-23.

Moynihan, Donald P. (2008), The Dynamics of Performance Management: Constructing Information and Reform, Washington, DC: Georgetown University Press.

Newland, C. (2012), 'Values and dignity in public administration: post NPM global fracture and search for human dignity and reasonableness', Public Administration Review, 72 (2), 293-301.

Pisano, M. (2013), 'Demography is Economic Destiny', America 2050, Regional Plan Association, pp. 3-4.

Pisano, M. and R.F. Callahan (2012), 'Case study I: fiscal sustainability in Los Angeles County', National Civic Review, 101 (1), 11-17.

Pisano, M. and R.F. Callahan (2013), 'County of San Bernardino', National Civic Review, $102(1), 3-6$.

Rubio-Cortes, G. (2012), 'Case study III: Whittier Union High School District fiscal solutions', National Civic Review, 101 (1), 24-9.

Southern California Association of Governments (1994), Regional Comprehensive Plan, Los Angeles, CA: SCAG.

Southern California Association of Governments (2004), Compass: Charting the Course for a Sustainable Southland, Los Angeles, CA: SCAG.

Southern California Association of Governments (2008), Comprehensive Regional Plan, Los Angeles, CA: SCAG.

United States General Accountability Office (US GAO) (2012), 'State and local fiscal outlook: April 12th update', available at http://www.gao.gov/assets/590/589908.pdf.

Wang, X., C.V. Hawkins, N. Lebredo and E.M. Berman (2013), 'Capacity to sustain sustainability: a study of US cities', Public Administration Review, 72 (6), 841-52. 
This book chapter is copyrighted by Edward Elgar Pub. Ltd. 2014. Any download is for personal and private use only. 